\title{
From preferences on resolution time in risky bets to the modeling of complex financialized markets
}

This issue of Risk and Decision Analysis is devoted to innovations in modeling decisions under risk or in designing models for the class of markets described as "financialized".

\section{Time resolution of bets}

In their paper, Robin Pope and Reinhardt Selten argue that bets are inscribed in a temporal and not only outcome substantial reference frame and that, in their view, the models which have been offered in the past to model this feature of decision making are not satisfactory. They take in particular issues with Kreps and Porteus [3,4] contributions. One of the interesting aspects of their paper is that they offer a set of axioms on which to rely in order to properly tackle the problem. These axioms lead to the proof that taking the expectation of any kind of utility - in particular of any Von Neumann-Morgenstern utility function - cannot be, indeed a satisfactory treatment of the issue.

The issue is rather tricky, because it is open to discussions by economic agents. Not knowing whether my lottery ticket will make me really rich may be part of my pleasure of gambling, this being true for many buyers of such tickets. But "subprime" credit buyers, having acquired some house, the mortgage of which has to be repaid, might fall on opportunities to buy additional credit to repay the next installments and under such circumstances, may hate not knowing whether their lottery ticket will make them rich - and therefore make useless for them to buy additional credit or not. Von Neumann and Morgenstern, in their celebrated Theory of Games and Economic Behavior, had made clear that they had no intention to deal with such issues. Rather, their seminal work was intended to deal with the issue to value risky assets of individuals, so that, for example, individuals would know how to trade risky against non-risky assets considered in games outcomes. Only such knowledge would allow dealing with the issue of side-payments in games. Their problem had no link whatsoever with time - their model being static - neither with any kind of preference on time directly nor with preference on the pleasure of gambling or impatience to know, etc. However, as has been argued by Drèze and Modigliani [1], Mossin [5], Spence and Zeckhauser [7], to quote only the seminal contributions, these issues cannot, in many practical situations, be considered separately from the preferences on outcome. The problem is then to derive actual preferences from 'expected utility on outcome' considered as a counterfactual: all contributions have shown that the notion of a simple integral like expected utility can hardly be maintained, except the stream of research initiated by Kreps and Porteus [3], which is criticized here.

One sees in any case only two possibilities open: either rely on an approximation or modify expected utility. Pope has consistently advocated that modelers should choose the second alternative - in a different way than Kreps and Porteus - and started to progressively define the conditions to impose then on the analysis, in a series of papers to which Pope and Selten's present paper refer extensively. Their present paper can be considered a climax of that stream of research, in that it offers the most general and rigorous analysis of their problem, thus complementing on this specific point Von Neumann and Morgenstern's seminal analysis [8]. 


\section{The issue of financialization and market modeling}

When taking risky positions connecting commodity markets and financial markets, investors may be expected to have preferences on uncertainty resolution, which would make any application of expected utility to their behavior somehow dubious. As a matter of fact, this observation contributes to relegate rational expectations of speculators to the attic of worn out accessories. The role of "middlemen" on financialized markets - among them short term investors, often speculators - is thus of decisive importance, both for practical considerations but also for market modeling. The impacts of their bets are modeled, in the paper titled "Boundedly rational exuberance in agricultural commodity markets", by considering the proportion between two types of them, the naïve ones and the conservative ones, the said proportion depending on some of the standard economic and physical quantities which define a state of the market system. This bounded rationality scheme circumvents the intricacies which expected utility would lead to here.

Farmers also are assumed to adopt a boundedly rational behavior, forming their anticipations by memorizing the recent prices and context, adjusting their expectation of current revenues as a certainty equivalent derived from this empirically memorized price distribution, which they in addition adjust through a context factor (taken here as being a transform of the speed of revenues changes in recent years). Figure 1 sum- marizes the approach, which combines a psychological dynamics with a more familiar, more standard, market dynamics.

Clearly, financialized markets, far from being simply markets, the outputs of which are being used as underlyings for financial transactions, are characterized by specific microstructures - the Walrasian approximation of the 'auctioneer' ceases to be acceptable in the case of bargaining markets, which represent the essentials of the transactions throughout the world on commodity markets - and some decisive role played by "middlemen" [2]. What is missing in the modeling presented below by Munier is the general interdependence with the rest of the economy. This is simply evoked in the article, as it would have been too lengthy to describe the whole system of models which is at the root of the 'Momagri simulation system'. Some early simulations are simply reported in the paper. They reveal results which could not have been obtained within the standard framework of market analysis, at least when endowed with estimated and/or reasonably set parameter values. The simulations obtained are much closer to observations of facts than standard models are. This suggests an aggiornamento in modeling markets being struck by a fair amount of financialization.

In their "Comments on Munier", Willi Semmler and Lucas Bernard [6] make extremely interesting points. They dwell on the market adjustment mechanisms at work in Munier's paper, and conclude that the paper uses the two available mechanisms - perhaps a feature of the specific micro structure of agricultural commodities markets.

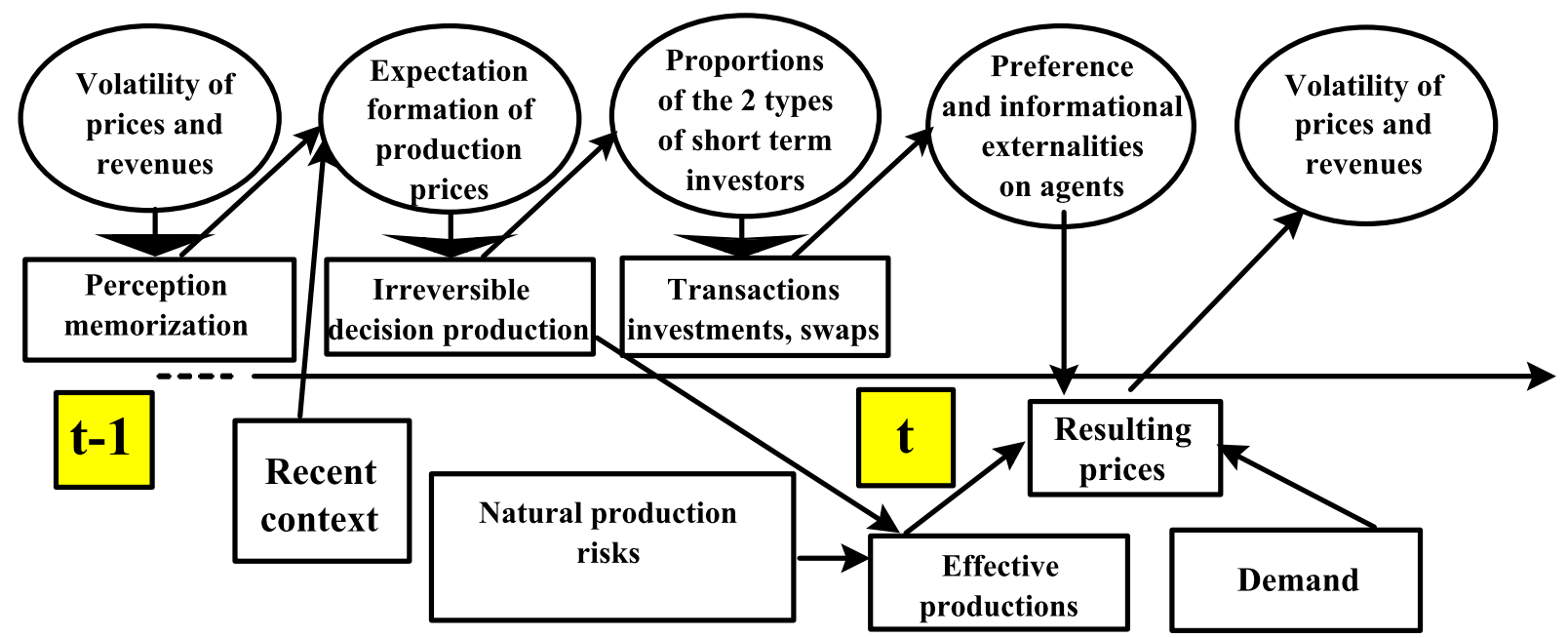

Fig. 1. Modeling financialized markets: above the line - the interplay of psychologies; below the line - the economic physical quantities and prices; across the line - the interrelations of both, a dominant feature in financialized markets. (The colors are visible in the online version of the article.) 
Non-renewable resources - ores and energy fossils exhibit, however, even more volatile prices than agricultural products, which are to a large extent renewable ones: Semmler and Bernard emphasize this point The difference, in their view, lies in the trend property of the former category - ores and metals - and the absence of clear trend for the second category - agricultural food or raw materials. Their opinion is interesting, for it goes against frequently asserted claims that food prices will from now on go up.... The authors make their point on the basis of statistics displayed in their Table 1.

A very interesting part of their "Comments..." is the illustration of the other aspect of "financialization" than the speculative short term investment, on which Munier's paper concentrates exclusively. They illustrate quite rightly, with a strength which some readers might feel frightening, indeed, what possibilities financialization has been opening on agricultural commodities markets and on a few others. One should be wary.

The "Reply to Semmler and Bernard" sketches what the debate on the above points is and will become. The most important point - which contains all the other ones, in some sense - is the issue of the Walrasian paradigm of the auctioneer or, put more scientifically, if less illustratively, the issue of "non-tâtonnement" market modeling. Munier argues that it might be a fairly acceptable approximation to price determination on many markets - with all the known and possible variations in the basic axioms of pure competition on perfect markets, of course - but not at all in the case of financialized markets. Semmler and Bernard may hold more radical views and consider - perhaps - that the tâtonnement process is to be rejected altogether.... The debate on this point has been opened in this special issue, dwelling on the character of eventually complex systems which our markets may reveal in the 21 st century.

\section{References}

[1] J.H. Drèze and F. Modigliani, Consumption decisions under uncertainty, Journal of Economic Theory 5 (1972), 308-335.

[2] D. Friedman, Market theories evolve, and so do markets, Journal of Economic Behavior and Organization 63 (2007), 247255.

[3] D.M. Kreps and E.L. Porteus, Temporal resolution of uncertainty and dynamic choice theory, Econometrica 46 (1978), 185-200.

[4] D.M. Kreps and E.L. Porteus, Temporal von NeumannMorgenstern and induced preferences, Journal of Economic Theory 20 (1979), 81-109.

[5] J. Mossin, A note on uncertainty and preferences in a temporal context, American Economic Review 59 (1969), 172-174.

[6] W. Semmler and L. Bernard, "Boundedly rational exuberance in commodity markets" - Some comments on Bertrand Munier, Risk and Decision Analysis 2(1) (2010/2011), 51-58 (this issue).

[7] M. Spence and R. Zeckhauser, The effect of the timing of consumption decisions and the resolution of lotteries on the choice of lotteries, Econometrica 40 (1972), 401-403.

[8] J. Von Neumann and O. Morgenstern, Theory of Games and Economic Behavior, Princeton University Press, Princeton, NJ, 1953. 